\title{
Efeito antibacteriano do vinagre de arroz e qualidade microbiológica de sushis comercializados na cidade de Brasília, Distrito Federal, Brasil
}

\author{
Antibacterial effect of rice vinegar and microbiological quality \\ of sushi marketed in the city of Brasilia, Distrito Federal, Brazil
}

\author{
Flávia Bianca Amaral Alves ${ }^{1}$, Karolina Oliveira Gomes ${ }^{1}$, Morgana Muniz Carrijo", \\ Letícia Fernandes Silva Rodrigues ${ }^{1}$, Izabel Cristina Rodrigues da Silva ${ }^{1}$, \\ Daniela Castilho Orsi ${ }^{1 *}$ (iD \\ ${ }^{1}$ Universidade de Brasília (UnB), Faculdade de Farmácia, Laboratório de Controle de Qualidade, Brasília/DF - Brasil \\ *Corresponding Author: Daniela Castilho Orsi, Universidade de Brasília (UnB), Faculdade de Farmácia, \\ Laboratório de Controle de Qualidade, Centro Metropolitano, Conjunto A, lote 01, Ceilândia, CEP: 72220-900, \\ Brasília/DF - Brasil, e-mail: danielacastilhoorsi@gmail.com
}

Cite as: Alves, F. B. A., Gomes, K. O., Carrijo, M. M., Rodrigues, L. F. S., Silva, I. C. R., \& Orsi, D. C. (2021)

Antibacterial effect of rice vinegar and microbiological quality of sushi marketed in the city of Brasília, Distrito

Federal, Brazil. Brazilian Journal of Food Technology, 24, e2020050. https://doi.org/10.1590/1981-6723.05020

\begin{abstract}
Resumo
O sushi é um alimento pronto para consumo composto de arroz acidificado com vinagre e recheio de peixes crus e vegetais. $\mathrm{O}$ ácido acético do vinagre diminui o $\mathrm{pH}$ do arroz e auxilia na conservação do sushi por retardar o crescimento microbiano. O objetivo deste estudo foi avaliar o efeito antibacteriano do vinagre de arroz mediante determinação da sua concentração inibitória mínima (CIM) e concentração bactericida mínima (CBM) e determinar a qualidade microbiológica de sushis comercializados na cidade de Brasília, Distrito Federal. Para as análises microbiológicas, dez amostras de sushi foram coletadas em restaurantes especializados em culinária oriental e dez amostras de sushi foram coletadas em locais não especializados em culinária oriental, como supermercados e padarias, totalizando 20 amostras. As análises realizadas foram contagem total de bactérias mesófilas e psicrotróficas, determinação de coliformes totais e coliformes termotolerantes, contagem de Staphylococcus aureus, pesquisa de Salmonella spp. e identificação molecular de $S$. aureus por PCR. O vinagre de arroz teve efeito antibacteriano tanto para as bactérias Gram-positivas (S. aureus e B. cereus) quanto para as bactérias Gramnegativas (S. enterica e E. coli) testadas neste estudo. Os valores de CBM variaram de 3 a $50 \mathrm{mg}$ de ácido acético $/ \mathrm{mL}$ e os valores de CIM variaram de 2,5 a 3,5 mg de ácido acético/ $\mathrm{mL}$. A maioria das amostras de sushi avaliadas neste estudo (80\%) estava em condições microbiológicas aceitáveis para o consumo, de acordo com a legislação brasileira. No entanto, quatro amostras (20\%) excederam o limite aceitável para S. aureus, portanto estavam impróprias para consumo. Essas amostras impróprias para consumo eram provenientes dos restaurantes especializados em culinária oriental. A presença elevada de bactérias $S$. aureus nessas amostras de sushi indica condições higiênicas inapropriadas, por se tratar de uma bactéria procedente de manipulação humana inadequada.
\end{abstract}

Palavras-chave: Alimento pronto para consumo; Microbiologia; Higiene; Ácido acético; Concentração inibitória mínima; Concentração bactericida mínima. 


\begin{abstract}
Sushi is a ready-to-eat food composed of rice acidified with vinegar and stuffing of raw fish and vegetables. The acetic acid in the vinegar reduces the $\mathrm{pH}$ of the rice and helps in the conservation of the sushi, decreasing the microbial growth. This study aimed to evaluate the antibacterial effect of rice vinegar by determining its minimum inhibitory concentration (MIC) and minimum bactericidal concentration (MBC); and to determine the microbiological quality of sushi marketed in the city of Brasilia, Distrito Federal. We performed microbiological analysis in 10 samples of sushi collected in restaurants specialized in oriental cuisine and 10 samples of sushi collected in places not specialized in oriental cuisine such as supermarkets and bakeries, totaling 20 samples. The analyzes performed were total count of mesophilic and psychrotrophic bacteria, determination of total coliforms and thermotolerant coliforms, count of Staphylococcus aureus, research of Salmonella spp., and the molecular identification of S. aureus by PCR. Rice vinegar had an antibacterial effect for gram positive bacteria (S. aureus and B. cereus) and for gram negative bacteria (S. enterica and E. coli). MBC values ranged from 3.0 to $50.0 \mathrm{mg}$ acetic acid/mL and MIC values ranged from 2.5 to $3.5 \mathrm{mg}$ acetic acid/mL. Most of the sushi samples evaluated in this study (80\%) presented acceptable microbiological conditions for consumption according to Brazilian legislation. However, 4 samples (20\%) exceeded the acceptable limit for $S$. aureus and were considered unfit for consumption. The unfit for consumption samples were from restaurants specialized in oriental cuisine. The high presence of $S$. aureus bacteria in these sushi samples indicates inappropriate hygienic conditions, as this is a bacterium normally associated to inadequate human manipulation.
\end{abstract}

Keywords: Ready-to-eat food; Microbiology; Hygiene; Acetic acid; Minimum inhibitory concentration; Minimum bactericidal concentration.

\title{
1 Introdução
}

O sushi teve origem nos países asiáticos, como forma de conservação do peixe, onde este era consumido fermentado e o arroz era usado no processo de fermentação para a produção de ácido láctico. No século XVI, o vinagre de arroz começou a ser adicionado ao sushi para reduzir seu tempo de preparo. Esse tipo de sushi tinha um sabor melhorado em relação ao original e, assim, surgiu o sushi usando vinagre, arroz cozido e peixe fresco, eliminando o processo de fermentação (Feng, 2012; Lee \& Heacock, 2014).

O sushi é um alimento pronto para consumo composto de arroz acidificado com vinagre, contendo cobertura ou recheio de peixes crus e vegetais. O tipo mais comum de apresentação do sushi é um bolinho de arroz enrolado externamente com folha de alga marinha denominada nori e contendo como recheio peixes, legumes, frutas ou ovos (Lee \& Heacock, 2014; Ramires et al., 2020).

No preparo do sushi, o arroz cozido ainda quente é acidificado com vinagre para facilitar a mistura da solução ácida. $\mathrm{O}$ arroz acidificado deve ter $\mathrm{pH}$ de 4,6 ou menos. $\mathrm{O}$ ácido acético do vinagre diminui o $\mathrm{pH}$ do arroz o suficiente para retardar o crescimento microbiano, especialmente de Bacillus cereus e Staphylococcus aureus (Feng, 2012; Lee \& Heacock, 2014).

Com o crescente aumento do consumo dos sushis nas grandes cidades brasileiras, aumentou-se a preocupação com a possibilidade de veiculação de doenças transmitidas por alimentos. A preocupação com a segurança alimentar do sushi é grande, principalmente pelo fato de ser perecível e consumido sem processamento térmico, requerendo condições higiênico-sanitárias adequadas a seu preparo. Ao preparar o sushi, o contato direto com as mãos dos manipuladores pode levar à contaminação por bactérias potencialmente patogênicas (Ramires et al., 2020; Souza et al., 2015).

O sushi é um alimento à base de peixe cru. Matéria-prima de boa qualidade é essencial para a segurança desse alimento, pois a microbiota do pescado reflete a água onde ele vive. O lançamento de esgotos sem tratamento nas águas de lagos, rios e mar contamina o pescado com bactérias patogênicas, como Escherichia coli e Salmonella (Souza et al., 2015; International Commission on Microbiological Specifications for Foods, 
2005). Outro fator preocupante é o uso de vegetais crus nos recheios dos sushis. Esses vegetais aumentam a possibilidade de contaminação, pois erros quanto à higienização e à manipulação podem veicular microrganismos patogênicos (Lorentzen et al., 2012).

Assim, o presente estudo teve como objetivo avaliar o efeito antibacteriano do vinagre de arroz pela determinação da concentração inibitória mínima (CIM) e da concentração bactericida mínima (CBM) deste em relação a diferentes bactérias e determinar a qualidade microbiológica de sushis comercializados na cidade de Brasília, Distrito Federal.

\section{Material e métodos}

\subsection{Determinação da Concentração Inibitória Mínima (CIM) e da Concentração Bactericida Mínima (CBM) do vinagre de arroz}

A determinação da CIM e da CBM do vinagre de arroz foi realizada de acordo com Clinical and Laboratory Standards Institute (2015), que define CIM como a menor concentração de um agente antimicrobiano que impede o crescimento de um microrganismo determinado por turbidez em testes de sensibilidade por diluição em caldo. De acordo com Clinical and Laboratory Standards Institute (1999), a CBM é definida como a menor concentração de um agente antimicrobiano capaz de reduzir a contagem microbiana em 99,9\%.

Os inóculos utilizados foram cepas de bactérias: Staphylococcus aureus ATCC 25923, Bacillus cereus ATCC 14579, Escherichia coli ATCC 25922 e Salmonella enteritidis ATCC 14028. Os inóculos foram preparados por meio de suspensão direta do crescimento microbiano em caldo Luria Bertani (LB) (HiMedia ${ }^{\circledR}$ ) com turvação equivalente a 0,5 da escala de McFarland ( $\left.1,0 \times 10^{8} \mathrm{UFC} / \mathrm{mL}\right)$, sendo ajustada entre 0,08 e 0,10 de densidade óptica a $625 \mathrm{~nm}$ em espectrofotômetro. Foram realizadas diluições em caldo LB das culturas na concentração de 0,5 na escala de McFarland na ordem de 1:150, resultando em concentração de $1,0 \times 10^{6} \mathrm{UFC} / \mathrm{mL}$.

O vinagre foi diluído em caldo LB em diferentes concentrações. Então, adicionaram-se, em tubos estéreis, $1,0 \mathrm{~mL}$ do inóculo na concentração de $1,0 \times 10^{6} \mathrm{UFC} / \mathrm{mL}$ e $1,0 \mathrm{~mL}$ das diferentes concentrações de vinagre, resultando em uma concentração final de bactérias de 5,0 x $10^{5} \mathrm{UFC} / \mathrm{mL}$. Como controle positivo (com crescimento das bactérias), foram utilizados $1,0 \mathrm{~mL}$ do inóculo na concentração de $1,0 \times 10^{6} \mathrm{UFC} / \mathrm{mL}$ e $1,0 \mathrm{~mL}$ de caldo LB. Como controle negativo (inibição do crescimento das bactérias), foram utilizados $1,0 \mathrm{~mL}$ do inóculo na concentração de $1,0 \times 10^{6} \mathrm{UFC} / \mathrm{mL}$ e $1,0 \mathrm{~mL}$ de vinagre.

Os tubos foram incubados a $37^{\circ} \mathrm{C}$ por 18 horas e, para a determinação da CIM, a leitura de turbidez foi realizada a $625 \mathrm{~nm}$ em espectrofotômetro. Para a determinação da CBM, as diluições foram plaqueadas em ágar Mueller Hinton e incubadas a $37^{\circ} \mathrm{C}$ por 18 a 24 horas e a CBM foi determinada na menor concentração em que não foram observadas colônias nas placas.

\subsection{Coleta, preparo das amostras e análises microbiológicas}

Para as análises microbiológicas, foram coletadas dez amostras de sushi em restaurantes especializados em culinária oriental e dez amostras de sushi em locais não especializados em culinária oriental, como supermercados e padarias, totalizando 20 amostras em 15 diferentes estabelecimentos comerciais do Distrito Federal. As amostras coletadas foram adequadamente acondicionadas e conduzidas ao laboratório, onde foram imediatamente analisadas.

Todas as amostras foram analisadas em três repetições, ou seja, foram retiradas três alíquotas de cada embalagem e os resultados foram expressos como média e desvio padrão. Para o preparo das amostras, foram pesadas $25 \mathrm{~g}$ de cada amostra e diluídas em $225 \mathrm{~mL}$ de água peptonada a $0,1 \%(\mathrm{p} / \mathrm{v})$. O material foi 
homogeneizado, obtendo-se, desta forma, a primeira diluição $\left(10^{-1}\right)$. A partir da primeira diluição, obtiveramse as demais diluições decimais (até $10^{-4}$ ).

Para a contagem total de bactérias mesófilas e psicrotróficas, as diluições de cada amostra foram semeadas, pelo método de superfície, em placas de Petri contendo o meio de cultivo ágar padrão para contagem (Acumedia ${ }^{\circledR}$ ). As placas foram incubadas a $37^{\circ} \mathrm{C}$, por $24 \mathrm{~h}$, para bactérias mesófilas e a $7{ }^{\circ} \mathrm{C} \pm 1{ }^{\circ} \mathrm{C}$, por sete dias, para bactérias psicrotróficas. Os resultados obtidos foram expressos em $\log \mathrm{UFC} / \mathrm{g}$.

Para a determinação do número mais provável (NMP) de coliformes totais e termotolerantes, as amostras foram analisadas conforme a técnica de tubos múltiplos, iniciando-se com o teste presuntivo, que consiste na inoculação de cada diluição das amostras em caldo lauril sulfato triptose (HiMedia ${ }^{\circledR}$ ). Os tubos foram incubados a $37^{\circ} \mathrm{C}$ por $24 \mathrm{~h}$. A positividade do teste caracterizou-se pela turvação do caldo com a produção de gás nos tubos de Durham. Alíquotas dos tubos positivos no teste presuntivo foram inoculadas, simultaneamente, em tubos de ensaio contendo caldo verde brilhante bile lactose a $2 \%\left(\mathrm{Kasvi}^{\circledR}\right.$ ) (para a confirmação de coliformes totais) e caldo Escherichia coli (Kasvi ${ }^{\circledR}$ ) (para a confirmação de coliformes termotolerantes). Os tubos foram incubados em estufa bacteriológica a $37{ }^{\circ} \mathrm{C}$, por $24 \mathrm{~h}$, para o teste de coliformes totais e em banho-maria a $45{ }^{\circ} \mathrm{C}$, por $24 \mathrm{~h}$, para o teste de coliformes termotolerantes. Os resultados obtidos foram expressos em $\log \mathrm{NMP} / \mathrm{g}$.

Para a pesquisa de Salmonella spp., a diluição $10^{-1}$ das amostras foi incubada a $37^{\circ} \mathrm{C}$ por $24 \mathrm{~h}$. Após a incubação, pipetou-se $1 \mathrm{~mL}$ das alíquotas do caldo de enriquecimento para tubos de ensaio contendo $10 \mathrm{~mL}$ de caldo seletivo tetrationato com iodo. As amostras foram homogeneizadas e incubadas a $37{ }^{\circ} \mathrm{C}$ por $24 \mathrm{~h}$. Após a incubação, procedeu-se à técnica de isolamento, em que, a partir de cada tubo, semearam-se placas de Petri contendo o meio de cultivo ágar Salmonella Shigella $\left(\mathrm{Kasvi}^{\circledR}\right)$ e ágar xilose-lisina-desoxicolato $\left(\right.$ HiMedia ${ }^{\circledR}$ ). As placas foram incubadas a $37{ }^{\circ} \mathrm{C}$ por $24 \mathrm{~h}$. As colônias suspeitas de Salmonella spp. foram transferidas para tubos inclinados contendo o meio de cultivo ágar Três Açúcares e Ferro (Kasvi ${ }^{\circledR}$ ).

Para a contagem de Staphylococcus aureus, cada uma das diluições das amostras foi semeada, pelo método de superfície, em placas de Petri contendo o meio de cultivo ágar Sal Manitol (Kasvi $\left.{ }^{\circledR}\right)$. As placas foram incubadas a $37^{\circ} \mathrm{C}$ por $48 \mathrm{~h}$. As colônias suspeitas de $S$. aureus foram reisoladas em tubos de ágar Sal Manitol e submetidas à coloração de Gram e identificação molecular pela técnica de reação em cadeia da polimerase (PCR). Para a identificação de S. aureus, foi utilizado o fragmento de 303 pares de base referente ao gene coagulase (CoA gene) e o primer construído é apresentado na Tabela 1.

Tabela 1. Sequência do primer usado para identificação do gene CoA de S. aureus.

\begin{tabular}{cccc}
\hline Primer & Sequência 5' $\mathbf{~ 3 ~}^{\prime}$ & Produto amplificado & Espécie \\
\hline CoA foward & GATCTTCGCGTGATACGTCA & $303 \mathrm{pb}$ & S. aureus \\
\hline CoA reverse & GTTCGTGCAATGTTTTGTCC & & \\
\hline
\end{tabular}

Para extração do DNA, as colônias isoladas foram inoculadas, individualmente, em caldo Brain Heart Infusion (HiMedia ${ }^{\circledR}$ ) e incubadas a $37{ }^{\circ} \mathrm{C}$, por $18 \mathrm{~h}$, e a extração do DNA foi realizada de acordo com o protocolo proposto no kit comercial Plasmid DNA purification MACHEREY-NAGEL ${ }^{\circledR}$. A qualidade e a quantidade de DNA extraído foram determinadas por eletroforese em gel de agarose, em comparação com o padrão de massa molecular DNAl/HindIII marcador de 100 pb (JENA $\left.{ }^{\circledR}\right)$.

Após a extração do DNA, a amplificação de fragmentos de genes foi realizada utilizando o termociclador Techne ${ }^{\circledR}$ modelo TC-512. As condições de termociclagem foram $50^{\circ} \mathrm{C}$ por $2 \mathrm{~min}, 95^{\circ} \mathrm{C}$ por 2 min e 40 ciclos de desnaturação a $95^{\circ} \mathrm{C}$ por $15 \mathrm{~s}$, seguida de $60^{\circ} \mathrm{C}$ por $30 \mathrm{~s}$, para o anelamento dos oligonucleotídeos e $72^{\circ} \mathrm{C}$ por $30 \mathrm{~s}$ para a extensão dos fragmentos. Foram utilizados $2,5 \mu \mathrm{L}$ de tampão (10 mM de Tris e $50 \mathrm{mM}$ de $\mathrm{KCl}), 0,7 \mu \mathrm{L}$ de $\mathrm{MgCl}_{2}, 1,5 \mu \mathrm{L}$ de dNTPs $(2,5 \mathrm{mM}), 0,5 \mu \mathrm{L}$ de Taq-Polimerase 
$\left(\right.$ Cenbiot $\left.^{\circledR}, 5 \mathrm{U} / \mu \mathrm{L}\right), 1,5 \mu \mathrm{L}$ de oligonucleotídeos foward e reverse $(10 \mu \mathrm{M})$, completando com água MilliQ para um volume final de $25 \mu \mathrm{L}$ por reação, com a amplificação de $10 \mathrm{ng}$ de DNA extraído da amostra bacteriana. Os produtos de PCR foram submetidos à eletroforese em gel de agarose, contendo brometo de etídeo e visualizados sob iluminação ultravioleta. O marcador de massa molecular utilizado foi o $100 \mathrm{pb}$ DNAl/HindIII (JENA $\left.{ }^{\circledR}\right)$.

\subsection{Determinação do pH das amostras de sushi}

$\mathrm{O}$ pH das amostras de sushi foi determinado em pHmetro digital (Association of Official Analytical Chemists, 2019). As medidas foram realizadas em triplicata e os resultados foram expressos como média e desvio padrão.

\section{Resultados e discussão}

\subsection{Determinação da Concentração Inibitória Mínima (CIM) e da Concentração Bactericida Mínima (CBM) do vinagre de arroz}

Os valores de CIM e CBM para as bactérias $S$. aureus ATCC 25923, B. cereus ATCC 14579, E. coli ATCC 25922 e $S$. enterica ATCC 14028 obtidos para o vinagre de arroz estão apresentados na Tabela 2. O vinagre de arroz teve efeito antibacteriano tanto para as bactérias Gram-positivas ( $S$. aureus e B. cereus) quanto para as bactérias Gram-negativas ( $S$. enterica e E. coli) testadas neste estudo. Os valores de CBM variaram de 3,0 a 50,0 mg de ácido acético/mL, sendo $B$. cereus a bactéria mais sensível ao efeito bactericida do vinagre. Já os valores de CIM variaram de 2,5 a 3,5 mg de ácido acético/mL.

Tabela 2. Determinação da CIM e da CBM do vinagre de arroz.

\begin{tabular}{ccc}
\hline Bactérias testadas & CIM $(\mathbf{m g} / \mathbf{m L})$ & CBM $(\mathbf{m g} / \mathbf{m L})$ \\
\hline S. aureus ATCC 25923 & 3,5 & 10,0 \\
\hline B. cereus ATCC 14579 & 2,5 & 3,0 \\
\hline E. coli ATCC 25922 & 3,0 & 12,5 \\
\hline S. enterica ATCC 14028 & 3,5 & 50,0 \\
\hline
\end{tabular}

Os valores de CIM e CBM foram expressos em relação à quantidade de ácido acético no vinagre de arroz, ou seja, em mg de ácido acético por $\mathrm{mL}$.

Souza et al. (2018) reportaram resultados similares para E. coli, em que a CBM do vinagre foi de $15 \mathrm{mg}$ de ácido acético/mL e a CIM, de 2,5 mg de ácido acético/mL. Ainda no estudo de Souza et al. (2018), amostras de alface artificialmente contaminadas com E. coli foram lavadas com água e imersas em solução com $15 \mathrm{mg} / \mathrm{mL}$ de ácido acético, por 15 minutos. Esse tratamento reduziu a contagem de E. coli nas amostras de 3,27 para $0,76 \log \mathrm{UFC} / \mathrm{g}$.

No estudo de Batista et al. (2017), observou-se que os sushis apresentaram menores valores de pH (média de 5,0) em relação aos sashimis (média de 6,6). Esses menores valores de $\mathrm{pH}$ ocorrem pela adição de vinagre (ácido acético) ao arroz no preparo do sushi. O ácido acético resulta em diminuição dos valores de $\mathrm{pH}$ do sushi, contribuindo na conservação desse alimento, uma vez que certos microrganismos não possuem capacidade de crescer em $\mathrm{pH}$ mais ácido. 


\subsection{Determinação do pH dos sushis}

Observou-se que os valores de $\mathrm{pH}$ das amostras de sushi variaram de 3,87 a 4,58 (Tabela 3). Todas as amostras estavam com valor aceitável de pH, que é de, no máximo, 4,60 (Association of Food and Drug Officials, 2004).

Tabela 3. Determinação do pH das amostras de sushi.

\begin{tabular}{cccc}
\hline Locais especializados $^{\mathbf{a}}$ & $\mathbf{p H}$ & Locais não especializados $^{\mathbf{b}}$ & $\mathbf{p H}$ \\
\hline $\mathbf{1}$ & $4,32 \pm 0,00$ & $\mathbf{1 1}$ & $3,87 \pm 0,00$ \\
\hline $\mathbf{2}$ & $3,90 \pm 0,01$ & $\mathbf{1 2}$ & $3,86 \pm 0,01$ \\
\hline $\mathbf{3}$ & $4,15 \pm 0,01$ & $\mathbf{1 3}$ & $4,19 \pm 0,00$ \\
\hline $\mathbf{4}$ & $4,04 \pm 0,03$ & $\mathbf{1 4}$ & $4,10 \pm 0,02$ \\
\hline $\mathbf{5}$ & $4,55 \pm 0,00$ & $\mathbf{1 5}$ & $4,58 \pm 0,01$ \\
\hline $\mathbf{6}$ & $4,16 \pm 0,02$ & $\mathbf{1 6}$ & $4,33 \pm 0,00$ \\
\hline $\mathbf{7}$ & $4,04 \pm 0,00$ & $\mathbf{1 7}$ & $4,34 \pm 0,00$ \\
\hline $\mathbf{8}$ & $4,08 \pm 0,01$ & $\mathbf{1 8}$ & $4,05 \pm 0,01$ \\
\hline $\mathbf{9}$ & $4,57 \pm 0,00$ & $\mathbf{1 9}$ & $4,14 \pm 0,01$ \\
\hline $\mathbf{1 0}$ & $3,89 \pm 0,00$ & $\mathbf{2 0}$ & $4,34 \pm 0,02$ \\
\hline
\end{tabular}

${ }^{\mathrm{a} A m o s t r a s ~ 1-10 ~ c o l e t a d a s ~ e m ~ r e s t a u r a n t e s ~ e s p e c i a l i z a d o s ~ e m ~ c u l i n a ́ r i a ~ o r i e n t a l ; ~}{ }^{\mathrm{b}} \mathrm{Amostras}$ 11-20 coletadas em locais não especializados em culinária oriental.

Feng (2012) reportou resultados similares ao nosso estudo, em que as 30 amostras de sushi coletadas de restaurantes japoneses na cidade de Burnaby, Canadá, apresentaram valores de $\mathrm{pH}$ de 3,71-4,53. Já no estudo de Batista et al. (2017), os valores de pH das 36 amostras de sushi analisadas variaram de 4,35 a 6,94 e dos 18 restaurantes japoneses onde as amostras de sushi foram coletadas na cidade de Goiânia, 13 restaurantes $(72 \%)$ apresentaram sushis com valores de $\mathrm{pH}$ maiores que 4,60.

\subsection{Avaliação da qualidade microbiológica dos sushis}

Neste estudo, foram analisadas 20 amostras de sushi e os resultados das análises microbiológicas estão descritos na Tabela 4. Segundo a International Commission on Microbiological Specifications for Foods (1986), os microrganismos mesófilos e psicrotróficos são um dos indicadores microbiológicos da qualidade em alimentos mais frequentemente utilizados e têm contagem máxima recomendada de $7 \mathrm{log}$ UFC/g. No presente estudo, as contagens de bactérias mesófilas ( 0,57 a 5,75 log UFC/g) e psicrotróficas (2,92 a 6,06 log UFC/g) estavam dentro dos limites aceitáveis. As bactérias mesófilas possuem crescimento ótimo entre 25 a $40{ }^{\circ} \mathrm{C}$ e sua presença em quantidades aceitáveis indica que as condições de higiene e conservação dos alimentos estão adequadas (Germano \& Germano, 2011).

No estudo de Muscolino et al. (2014), foram reportadas contagens mais elevadas de bactérias mesófilas (5,00 a 8,18 log UFC/g) e psicrotróficas (4,70 a 7,13 log UFC/g) em amostras de sushi comercializadas nas cidades de Messina e Catania, Itália. As bactérias psicrotróficas são capazes de crescer em temperaturas de $7{ }^{\circ} \mathrm{C}$, porém a temperatura ideal de crescimento está entre 20 e $30^{\circ} \mathrm{C}$. A contagem de microrganismos psicrotróficos em quantidades elevadas indica possível deterioração dos alimentos refrigerados (Germano \& Germano, 2011). 
Efeito antibacteriano do vinagre de arroz e qualidade microbiológica de sushis comercializados na cidade de Brasília, Distrito Federal, Brasil

Alves, F. B. A. et al.

Tabela 4. Análises microbiológicas das amostras de sushi.

\begin{tabular}{|c|c|c|c|c|c|c|}
\hline & $\begin{array}{l}\text { Bactérias } \\
\text { mesófilas }\end{array}$ & $\begin{array}{c}\text { Bactérias } \\
\text { psicrotróficas }\end{array}$ & Coliformes totais & $\begin{array}{c}\text { Coliformes } \\
\text { termotolerantes }\end{array}$ & Salmonella & S. aureus \\
\hline \multicolumn{7}{|c|}{ Amostras coletadas em restaurantes especializados em culinária oriental } \\
\hline 1 & $4,81 \pm 0,14$ & $5,46 \pm 0,62$ & $2,53 \pm 0,45$ & $0,48 \pm 0,12$ & Ausente & $5,30 \pm 0,72$ \\
\hline 2 & $3,40 \pm 0,17$ & $5,44 \pm 0,15$ & $1,03 \pm 0,12$ & $0,53 \pm 0,52$ & Ausente & ND \\
\hline 3 & $3,45 \pm 0,14$ & $3,82 \pm 0,18$ & $1,50 \pm 0,69$ & $1,11 \pm 0,56$ & Ausente & $2,45 \pm 0,21$ \\
\hline 4 & $4,77 \pm 0,04$ & $4,30 \pm 0,17$ & ND & ND & Ausente & $3,72 \pm 0,19$ \\
\hline 5 & $5,72 \pm 0,06$ & $6,06 \pm 0,07$ & $1,29 \pm 0,25$ & $1,38 \pm 0,19$ & Ausente & $4,57 \pm 0,28$ \\
\hline 6 & $3,71 \pm 0,14$ & $4,69 \pm 0,27$ & $2,18 \pm 0,56$ & $0,57 \pm 0,58$ & Ausente & $2,96 \pm 0,51$ \\
\hline 7 & $2,10 \pm 0,17$ & $3,52 \pm 0,38$ & $1,22 \pm 0,22$ & $0,37 \pm 0,32$ & Ausente & $3,15 \pm 0,22$ \\
\hline 8 & $4,75 \pm 0,50$ & $3,62 \pm 0,20$ & $1,49 \pm 0,06$ & $0,74 \pm 0,38$ & Ausente & $2,96 \pm 0,20$ \\
\hline 9 & $4,63 \pm 0,83$ & $4,04 \pm 0,34$ & $1,69 \pm 0,35$ & $1,26 \pm 0,14$ & Ausente & $2,76 \pm 0,15$ \\
\hline 10 & $4,51 \pm 1,06$ & $4,36 \pm 0,75$ & $1,81 \pm 0,44$ & $1,26 \pm 0,42$ & Ausente & ND \\
\hline \multicolumn{7}{|c|}{ Amostras coletadas em locais não especializados em culinária oriental } \\
\hline 11 & $0,57 \pm 0,10$ & $3,74 \pm 0,72$ & $0,15 \pm 0,11$ & ND & Ausente & ND \\
\hline 12 & $2,61 \pm 0,28$ & $4,76 \pm 0,22$ & $0,26 \pm 0,17$ & $0,26 \pm 0,10$ & Ausente & ND \\
\hline 13 & $2,89 \pm 0,19$ & $2,92 \pm 0,15$ & $0,28 \pm 0,50$ & ND & Ausente & ND \\
\hline 14 & $2,80 \pm 0,70$ & $4,89 \pm 0,07$ & ND & ND & Ausente & ND \\
\hline 15 & $3,04 \pm 0,08$ & $4,39 \pm 0,10$ & $0,37 \pm 0,32$ & $0,18 \pm 0,15$ & Ausente & $2,66 \pm 0,10$ \\
\hline 16 & $3,26 \pm 0,31$ & $4,08 \pm 0,16$ & ND & ND & Ausente & ND \\
\hline 17 & $5,71 \pm 0,27$ & $4,69 \pm 0,17$ & $0,56 \pm 0,10$ & $0,56 \pm 0,10$ & Ausente & ND \\
\hline 18 & $5,34 \pm 0,33$ & $4,99 \pm 0,22$ & $2,85 \pm 0,33$ & $0,58 \pm 0,17$ & Ausente & $2,99 \pm 0,21$ \\
\hline 19 & $3,25 \pm 0,32$ & $4,57 \pm 0,31$ & $1,00 \pm 0,55$ & $0,48 \pm 0,00$ & Ausente & $2,46 \pm 0,40$ \\
\hline 20 & $5,75 \pm 0,88$ & $5,66 \pm 0,78$ & $2,69 \pm 0,33$ & $0,61 \pm 0,22$ & Ausente & $2,92 \pm 0,10$ \\
\hline
\end{tabular}

Amostras 1-10 coletadas em restaurantes especializados em culinária oriental; amostras 11-20: coletadas em locais não especializados em culinária oriental. Os resultados foram expressos como média \pm desvio padrão; ND: não detectado. Bactérias mesófilas, bactérias psicrotróficas e $S$. aureus: resultados expressos em $\log \mathrm{UFC} / \mathrm{g}$; coliformes totais e coliformes termotolerantes: resultados expressos em $\log \mathrm{NMP} / \mathrm{g}$.

A legislação brasileira (Brasil, 2019) não estabelece limites para o grupo dos coliformes totais nos alimentos prontos para consumo como sushi. Porém, é importante quantificar esse grupo, pois essas bactérias costumam ter seus níveis aumentados em alimentos manipulados e, dessa forma, funcionam como um indicador de higiene (International Commission on Microbiological Specifications for Foods, 2002; Moura et al., 2015). De acordo com a International Commission on Microbiological Specifications for Foods (2002), o valor máximo recomendado para o grupo dos coliformes totais é de $3 \log \mathrm{NMP} / \mathrm{g}$. O grupo dos coliformes termotolerantes possui como principal representante a bactéria Escherichia coli e sua presença em elevadas concentrações indica contaminação fecal recente do alimento e possível presença de enteropatógenos (Batista et al., 2017). Para coliformes termotolerantes, é permitida a presença de até $2 \log$ $\mathrm{NMP} / \mathrm{g}$ nos alimentos prontos para consumo como sushi (Brasil, 2019).

No presente estudo, as amostras apresentaram valores de coliformes totais de ND a 1,26 log NMP/g e das 20 amostras de sushi analisadas, 15 amostras (75\%) apresentaram coliformes termotolerantes, porém dentro 
dos limites permitidos pela legislação brasileira $(<2 \log \mathrm{NMP} / \mathrm{g})$. As amostras de sushi coletadas em restaurantes especializados em culinária oriental estavam mais contaminadas com coliformes termotolerantes do que as amostras coletadas em locais não especializados em culinária oriental. Das dez amostras de sushi coletadas em restaurantes, nove estavam contaminadas com coliformes termotolerantes (90\%). Das dez amostras de sushi coletadas em supermercados e padarias, seis estavam contaminadas com coliformes termotolerantes $(60 \%)$.

Dreckmann et al. (2016) reportaram resultados similares em dez amostras de sushi comercializadas em restaurantes orientais no Balneário Camboriú (SC): todas as amostras estavam com enumeração de coliformes termotolerantes dentro dos limites permitidos pela legislação brasileira. Guimarães et al. (2016), ao analisarem amostras de sushi coletadas em estabelecimentos de comida japonesa, nas cidades de Crato e Juazeiro do Norte (CE), verificaram que 24 das 30 amostras analisadas (80\%) apresentaram contagem elevada para coliformes totais. Porém, para o grupo de coliformes termotolerantes, todas as amostras estavam em conformidade com a legislação. Em contrapartida, no estudo de Souza et al. (2015), as amostras de sushi coletadas em restaurantes japoneses, nos municípios de João Pessoa (PB), mostraram elevada contaminação por coliformes termotolerantes, e 12 das $15(80 \%)$ excederam os limites aceitáveis para coliformes termotolerantes (máximo de $2 \log \mathrm{NMP} / \mathrm{g}$ ).

Na legislação brasileira, não é permitida a presença de Salmonella em alimentos como sushi (Brasil, 2019). Neste estudo, não houve presença de Salmonella nas amostras de sushi pesquisadas. Os estudos de Dreckmann et al. (2016), Muscolino et al. (2014) e Ramires et al. (2020) relataram resultados similares e não identificaram Salmonella em amostras de sushi comercializadas, respectivamente, em Balneário Camboriú (SC), Messina e Catania (Itália) e Pelotas (RS). Porém, Souza et al. (2015) identificaram Salmonella em duas amostras de sushi (13\%), comercializados na cidade de João Pessoa (PB), indicando a necessidade de controle mais rígido no preparo desses alimentos.

Staphylococcus aureus é uma bactéria que indica níveis de higiene relacionados à manipulação de alimentos e, quando presente em elevadas concentrações nos alimentos, pode produzir enterotoxinas causadoras de intoxicação alimentar (Hennekinne et al., 2012). Alimentos como sushi com valores de S. aureus superiores a $3 \log$ UFC/g são classificados como impróprios para consumo (Brasil, 2019).

Neste estudo, das 20 amostras de sushi analisadas, $12(60 \%)$ apresentaram bactérias $S$. aureus, tendo quatro delas (20\%) excedido o limite aceitável para $S$. aureus de $3 \mathrm{log}$ UFC/g. Essas amostras impróprias para consumo eram provenientes de restaurantes especializados em culinária oriental. As amostras de sushi coletadas em restaurantes estavam mais contaminadas com bactérias $S$. aureus do que as amostras coletadas em locais não especializados em culinária oriental. Das dez amostras de sushi coletadas em restaurantes, oito $(80 \%)$ estavam contaminadas com bactérias S. aureus. Das dez amostras de sushi coletadas em supermercados e padarias, quatro (40\%) estavam contaminadas com bactérias $S$. aureus.

No estudo de Souza et al. (2015), 87\% das amostras de sushi comercializadas na cidade de João Pessoa (PB) estavam contaminadas com bactérias $S$. aureus e das 15 amostras analisadas, cinco $(33,3 \%)$ apresentaram contagem de $S$. aureus acima de 3,00 log UFC/g. No estudo de Muscolino et al. (2014), bactérias $S$. aureus foram isoladas em 16 das 38 amostras $(42,1 \%)$ de sushi analisadas e as contagens variaram de 2,00 a $3,60 \log \mathrm{UFC} / \mathrm{g}$.

O sushi sofre intensa manipulação durante o preparo, assim, a falta de higiene durante a manipulação é o principal fator que determina a presença de $S$. aureus nesse tipo de alimento, uma vez que essa bactéria pode estar presente nas mãos e na mucosa oronasal do manipulador. Preparações muito manipuladas são consideradas de alto risco, especialmente quando elaboradas por pessoas sem treinamento adequado e conservadas em temperaturas inapropriadas (Batista et al., 2017; Souza et al., 2015).

As cepas $S$. aureus isoladas das amostras de sushi foram confirmadas por meio da detecção do gene Coa que codifica a enzima coagulase por PCR. A enzima coagulase é um importante fator de virulência para a 
bactéria $S$. aureus, causando coagulação do plasma mediante conversão do fibrinogênio em fibrina insolúvel para proteger a bactéria de fagocitose. A detecção do gene Coa ou da enzima coagulase por outras técnicas é considerada um padrão para identificar S. aureus (Javid et al., 2018).

\section{Conclusões}

A maioria das amostras de sushi avaliadas neste estudo (80\%) estava em condições microbiológicas aceitáveis para consumo, de acordo com a legislação brasileira. No entanto, quatro amostras provenientes de restaurantes especializados em culinária oriental (20\%) excederam o limite aceitável para S. aureus e estavam impróprias para consumo. Em geral, as amostras de sushi coletadas em restaurantes especializados em culinária oriental estavam mais contaminadas com coliformes termotolerantes e bactérias $S$. aureus do que as amostras coletadas em locais não especializados em culinária oriental. Esse resultado reforça a necessidade de melhorar o treinamento dos manipuladores nos restaurantes especializados em culinária oriental da cidade de Brasília, a fim de evitar manipulação inadequada, contaminação cruzada e temperatura inadequada de exposição do sushi, fatores que favorecem a proliferação dessas bactérias. $\mathrm{O}$ vinagre de arroz apresentou efeito antibacteriano tanto para as bactérias Gram-positivas (S. aureus e B. cereus) quanto para as bactérias Gram-negativas (Salmonella e E. coli) testadas, o que pode ter contribuído para a boa qualidade microbiológica da maioria das amostras de sushi.

\section{Referências}

Association of Food and Drug Officials - AFDO. (2004). Guidance for processing sushi in retail operations. Recuperado em 11 de março de 2020, de http://edis.ifas.ufl.edu/pdffiles/FS/FS11700.pdf

Association of Official Analytical Chemists - AOAC. (2019). Official methods of analysis (21st ed.). Gaithersburg: AOAC

Batista, C. M., Ribeiro, M. L. R., Souza, M. J. F., Borges, L. J., Ferreira, T. A. P. C., \& André, M. C. P. (2017). Microbiological and physicochemical qualities of sushi and sashimi from Japanese Restaurants in Brazil. Journal of Food and Nutrition Research, 5(10), 729-735. Recuperado em 11 de março de 2020, de http://pubs.sciepub.com/jfnr/5/10/2

Brasil. Agência Nacional de Vigilância Sanitária. (2019, dezembro 26). Estabelece as listas de padrões microbiológicos para alimentos (Instrução normativa $n^{\circ}$ 60, de 23 de dezembro de 2019). Diário Oficial [da] República Federativa do Brasil, Brasília.

Clinical and Laboratory Standards Institute - CLSI. (1999). Methods for Determining Bactericidal Activity of Antimicrobial Agents, Approved Guideline M26-A Wayne, Pennsylvania, USA.

Clinical and Laboratory Standards Institute - CLSI. (2015). Methods for dilution antimicrobial susceptibility tests for bacteria that grow aerobically, approved guideline M07-A10. Wayne, Pennsylvania, USA.

Dreckmann, M. V., Hintz, G. F. M., Lemos, M. P., Bramorski, A., Schmeling, T. B., \& Reis, M. (2016). Qualidade higienicossanitária de sushis e sashimis comercializados em restaurantes orientais de Balneário Camboriú, SC. Revista Higiene Alimentar, 30(252-253), 131-136. Recuperado em 11 de março de 2020, de https://pesquisa.bvsalud.org/portal/resource/pt/biblio-846839

Feng, C. H.-I. (2012). The tale of sushi: history and regulations. Comprehensive Reviews in Food Science and Food Safety, 11(2), 205-220. http://dx.doi.org/10.1111/j.1541-4337.2011.00180.x

Germano, P. M. L., \& Germano, M. I. S. (2011). Higiene e vigilância sanitária de alimentos: Qualidade das matérias-primas, doenças transmitidas por alimentos, treinamento de recursos humanos. São Paulo: Manole.

Guimarães, K. P., Silva, R. M. R., \& Guimarães, K. P. (2016). Investigação da qualidade microbiológica de sushis comercializados nas cidades de Crato e Juazeiro do Norte - CE. Revista E-Ciência, 4(2), 20-25. http://dx.doi.org/10.19095/rec.v4i2.166

Hennekinne, J.-A., De Buyser, M.-L., \& Dragacci, S. (2012). Staphylococcus aureus and its food poisoning toxins: Characterization and outbreak investigation. FEMS Microbiology Reviews, 36(4), 815-836. PMid:22091892. http://dx.doi.org/10.1111/j.1574-6976.2011.00311.x

International Commission on Microbiological Specifications for Foods - ICMSF. (1986). Sampling for microbiological analysis: Principles and specific applications. London: Blackwell Scientific Publications.

International Commission on Microbiological Specifications for Foods - ICMSF. (2002). Microrganisms in Foods 7: Microbiological testing in food safety management. New York: Kluwer Academic Publishers.

International Commission on Microbiological Specifications for Foods - ICMSF. (2005). Microorganisms in foods 6: Microbial ecology of food commodities, New York: Kluwer Academic Publishers.

Javid, F., Taku, A., Bhat, M. A., Badroo, G. A., Mudasir, M., \& Sofi, T. A. (2018). Molecular typing of Staphylococcus aureus based on coagulase gene. Veterinary World, 11(4), 423-430. PMid:29805205. http://dx.doi.org/10.14202/vetworld.2018.423-430 
Efeito antibacteriano do vinagre de arroz e qualidade microbiológica de sushis comercializados na cidade de Brasília, Distrito Federal, Brasil

Alves, F. B. A. et al.

Lee, C. J., \& Heacock, H. (2014). Safety and pH measurements of sushi rice in Japanese restaurants in Burnaby BC, Canada. Burnaby, BC: British Columbia Institute of Technology. Recuperado em 11 de março de 2020, de http://www.ncceh.ca/sites/default/files/BCIT-Lee-2014.pdf

Lorentzen, G., Breiland, M. S. W., Cooper, M., \& Herland, H. (2012). Viability of Listeria monocytogenes in an experimental model of nigiri sushi of halibut (Hippoglossus hippoglossus) and salmon (Salmo salar). Food Control, 25(1), $245-248$. http://dx.doi.org/10.1016/j.foodcont.2011.10.038

Moura, R. F., Costa, G. F. I., Araújo, C. D. L. I., Cunha, J. C. I., Silva Filho, C. R. M. I. I., \& Santos, J. G. I. I. I. (2015). Avaliação microbiológica de sushis a base de salmão preparados em restaurantes especializados em culinária japonesa da região do agreste paraibano. Alimentação Humana, 21, 16-22.

Muscolino, D., Giarratana, F., Beninati, C., Tornambene, A., Panebianco, A., \& Ziino, G. (2014). Hygienic-sanitary evaluation of sushi and sashimi sold in Messina and Catania, Italy. Italian Journal of Food Safety, 3(2), 1701. PMid:27800343. http://dx.doi.org/10.4081/ijfs.2014.1701

Ramires, T., Iglesias, M. A., Vitola, H. S., Núncio, A. S. P., Kroning, I. S., Kleinubing, N. R., Fiorentini, A. M., \& Silva, W. P. (2020). First report of Escherichia coli O157:H7 in ready-to-eat sushi. Journal of Applied Microbiology, 128(1), 301-309. PMid:31541508. http://dx.doi.org/10.1111/jam.14456

Souza, G., Spinosa, W., \& Oliveira, T. (2018). Sanitizing action of triple-strength vinegar against Escherichia coli on lettuce. Horticultura Brasileira, 36(3), 414-418. http://dx.doi.org/10.1590/s0102-053620180321

Souza, T. J. F. F., Silva, J. N., Silva Filho, C. R. M., \& Santos, J. G. (2015). Microrganismos de interesse sanitário em sushis. Revista do Instituto Adolfo Lutz, 3(74), 274-279. Recuperado em 11 de março de 2020, de

http://www.ial.sp.gov.br/resources/insituto-adolfo-lutz/publicacoes/rial/10/rial74_3_completa/pdf/artigosseparados/1662.pdf

Funding: None.

Received: Mar. 11, 2020; Accepted: Nov. 30, 2020 